\title{
Opportunistic Scavenging by Larval Spot-legged Treefrogs, Polypedates megacephalus (Anura: Rhacophoridae)
}

\author{
Krunal Trivedi ${ }^{1}$, Bartosz Nadolski ${ }^{2}$, and Pongthep Suwanwaree ${ }^{2}$ \\ 126, Kasturba Mahila Society, Palanpur patiya, Surat-395009, Gujarat, India (krunal.trivedi.7567@gmail.com) \\ ${ }^{2}$ School of Biology, Institute of Science, Suranaree University of Technology, Thailand 30000
}

$\mathrm{T}$ he Spot-legged Treefrog (Polypedates megacephalus), also known as the Hong Kong Whipping Frog, is abundant and widely distributed in tropical and subtropical central, southern, and southwestern China (including Hong Kong), northeastern India, northern Vietnam, and Thailand. It may also occur in Myanmar and Laos (Frost 2018; Lau 2009). These frogs occupy a wide range of habitats, including disturbed areas such as those converted to agricultural use and near human habitation. It breeds in still water. Foam nests

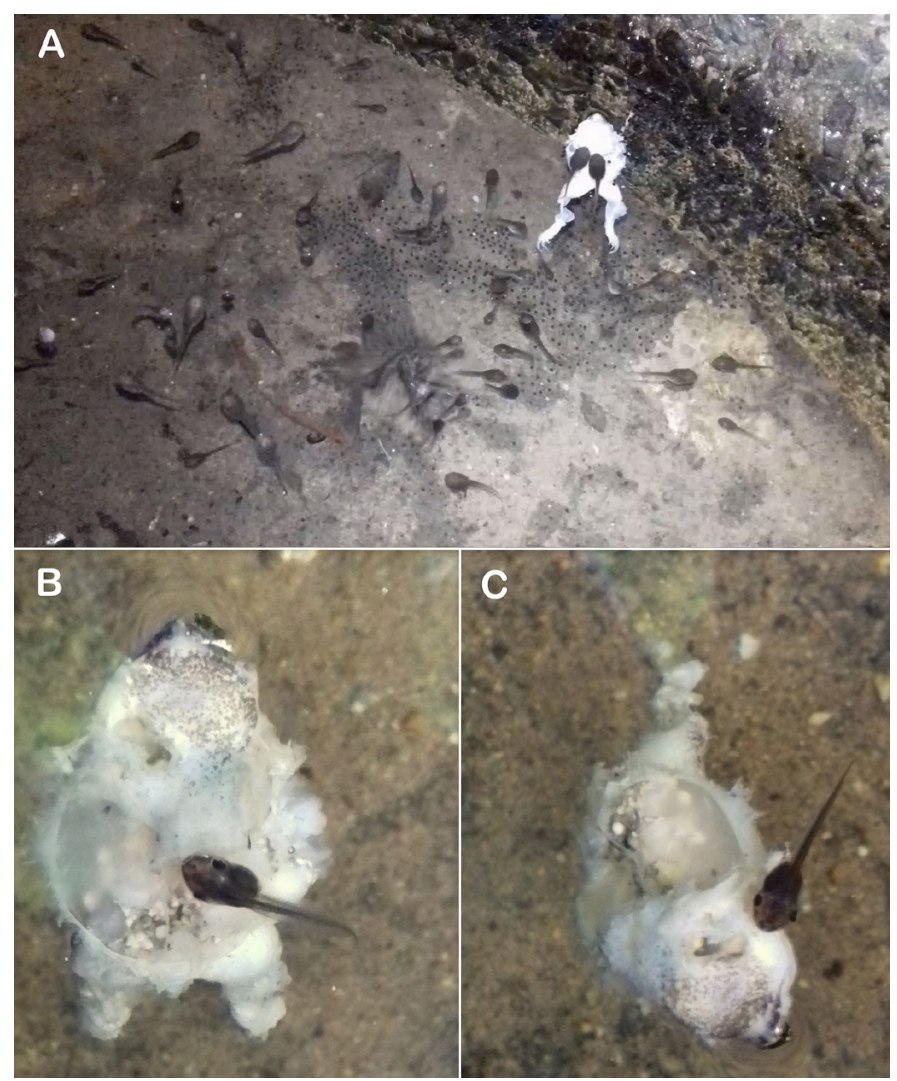

Fig. 1. Larval Polypedates megacephalus scavenging an unidentified frog carcass (A); closeup showing a tadpole scavenging the carcass (B \& C). Note the advanced state of decomposition of the frog. Photographs by Krunal Trivedi. have been found to contain 300-400 eggs and often are in shallow, still water, typically attached to emergent vegetation (Christy et al. 2007). Little is known about scavenging behavior in larval treefrogs, although Street et al. (2013) reported tadpoles of Osteopilus septentrionalis (Hylidae) scavenging on insects. Herein we report larval Polypedates megacephalus scavenging on a frog carcass.

At 2125 h on 31 May 2017, during a field survey at Sakaerat Biosphere Reserve, Thailand $\left(14.50299^{\circ} \mathrm{N}\right.$, $101.94901^{\circ} \mathrm{E}$; WGS 84), we observed P. megacephalus tadpoles scavenging on the remains of a frog floating in a freshwater tank (Fig. 1A) with a diameter of approximately $1 \mathrm{~m}$ and a depth of $12.7 \mathrm{~cm}$. We identified the tadpoles on the basis of their gray coloration, oval head and body shape, lateral eyes, silver-white venter, narrowly pointed tail fin, and downward-directed mouth. We initially observed a large group of tadpoles trying to feed on the carcass of the frog, but as the scavenging continued, only a few individuals were able to feed at a time (Fig. 1B). The scavenging continued for $32 \mathrm{~h}$ until the carcass was essentially gone. We were unable to identify the frog from the carcass as the body was at an advanced stage of decomposition when first encountered (Fig. 1C). To our knowledge, this is the first report of scavenging by larval P. megacephalus.

\section{Acknowledgement}

We are thankful to the team of the Sakaerat Najas Project for assisting with fieldwork. Thanks also to the Sakaerat Environmental Research Station and Director Surachit Waengsothorn for constant support and motivation.

\section{Literature Cited}

Christy, M.T., C.S. Clark, D.E. Gee II, D. Vice, D.S. Vice, M.P. Warner, C.L. Tyrrell, G.H. Rodda, and J.A. Savidge. 2007. Recent records of alien anurans on the Pacific Island of Guam. Pacific Science 61: 469-483.

Frost, D.R. 2018. Polypedates megacephalus. Amphibian Species of the World: An Online Reference. Version 6.0. American Museum of Natural History, New 
York, USA (http://research.amnh.org/vz/herpetology/amphibia/Amphibia/ Anura/Rhacophoridae/Rhacophorinae/Polypedates/Polypedates-megacephalus).

Lau, M.W.N., C. Wenhao, Y. Datong, and A. Ohler. 2009. Polypedates megacephalus. The IUCN Red List of Threatened Species 2009: e.T58957A11862153
(http://dx.doi.org/10.2305/IUCN.UK.2004.RLTS.T58957A11862153.en).

Street, K.B., J.S. Parmerlee, Jr, and R. Powell. 2013. Adventitious scavenging by Cuban Treefrog tadpoles, Osteopilus septentrionalis (Anura: Hylidae). Herpetology Notes 6: 33-34. 